NBER WORKING PAPER SERIES

PROJECT APRAISAL AND FOREIGN EXCHANGE CONSTRAINTS:

A SIMPLE EXPOSITION

Charles R. Blitzer

Partha Dasgupta

Joseph E. Stiglitz

Working Paper No. 2165

NATIONAL BUREAU OF ECONOMIC RESEARCH

1050 Massachusetts Avenue

Cambridge, MA 02138

February 1987

The research reported here is part of the NBER's research program in Taxation. Any opinions expressed are those of the authors and not those of the National Bureau of Economic Research. 
NBER Working Paper \#2165 February 1987

\section{Project Appraisal and Foreign Exchange Constraints: \\ A Simple Exposition}

\section{$\underline{\text { ABSTRACT }}$}

In an earlier paper, ${ }^{l}$ we showed that the value of shadow prices depends on how the government contemplates reequilibrating the economy to the perturbation associated with any project, except in the extreme case where the government has chosen all policy instruments optimally. Only under restrictive conditions will relative shadow prices for traded goods equal relative international prices. We develop here a general methodology for calculating shadow prices, which expresses the prices as a weighted average of domestic and international prices. The formulae provide the conditions under which the border price rule is valid. For instance, so long as there are non-traded goods, even if the government leaves tariffs unchanged (so that relative domestic prices of traded goods remain unchanged), unless the government completely neutralizes the induced change in domestic income, there will be changes in the prices of non-traded goods. These will preclude the use of the border price rule.

1 C. Blitzer, P. Dasgupta and J. E. Stiglitz (1981), "Project Appraisal and Foreign Exchange Constraints," Economic Journal, Vol. 91 , pp. 58-74.

Charles R. Blitzer

Energy Laboratory

MIT

Cambridge, MA 02139
Partha Dasgupta University of Cambridge Faculty of Economics and Politics

Sidgwick Avenue Cambridge CB39DD ENGLAND

Joseph E. Stiglitz

Department of Economics

Princeton University

Princeton, NJ 08544 
Project Appraisal and Foreign Exchonge Constraints:

A Simple Exposition 1

by

\author{
Charles R. Blitzer \\ Masechusetts Institute of Technology \\ Parthe Dasgupta \\ Canbridge University \\ Joseph E. Stiglitz \\ Princeton University
}

In our earlier peper, we raised three points:

(1) In general, any project has consequences for domestic income, government revenue, and foreign exchenge. Depending on which constrainte are binding, the government will have to adjust taxes, subsidies, expenditures, and foreign borrowing whenever new projecte are undertaken.

(2) The calculation of shadow prices depends on how the government contemplates re-equilibrating the economy to these perturbetions induced by the the project, excopt in the the rather extreme case where the government has chosen all policy instruments optimally, in which case the wolfare consequences of all forms of adjustment are identical.

(3) Only under certain restrictive conditions would relative shadow prices for traded goods equal relative international prices.

The general validity of these propositions is, by now, well establiahed. In spite of this, the "border price" rule (that shadow prices are proporional to border or world prices) continues to enjoy considerable

1 Financial support from the Mational Science Foundation and the MIT Canter for Energy Policy Research is gratefully acknowledged. 
popularity, partly because of the seemingly convenient simplification it provides for calculation purposes, and partly because of its political overtones, suggesting limited government interference in the market. If correct, our results have an important practical implication--namely, that the "border price" rule is applied too broadly, and should not be used unless the country in question actually follows one of a limited set of policies for which it is valid. We, therefore, welcome this opportunity to clarify our results and further explain their application.

Given the range of possible equilibrating mechanisms, the delineation of all circumstances under which shadow prices are proportional to international prices and the derivation of shadow price formulas when they are not equal to international prices is a complex matter beyond the scope of our original paper, the objective of which was to develop a general franework into which such problems should be cast. The authors of recent comments on our paper 2 argue that shadow prices may indeed be equal or proportional to international prices under somewhat more general conditions than a casual reading of our earlier paper would suggest. Rather than debating the questions of which set of assumptions is more appropriate or aseessing the consequences of any technical errors in the Dinwiddy-Teal piece, we believe it would be more useful to recast the problem in general terms to see what is at $188 u e$.

\section{A GEMERAL FORMULATION}

We suppose that the economy in question is initially (1.e., before the project) in some equilibrium. This equilibrium may or may not imply trade

2 Caroline Dinwiddy and Francis Teal, "Project Appraisal and Foreign Exchange Constraints: A Coment," and Edward Tower and Peter G. Warr, "On the Proportionality between World Prices and Shadow Prices Under Alternative Equilibrating Mechanisas." 
balance, a public deficit, or distortionary indirect taxes on trade. production, and consumption. The nature of the initial equilibrium by itself is not of importance for shadow price derivation, which depends only how a particular project effects the change in the equilibrium position.

To further siaplify the analysis, we essume: a) the level of the country's foreign trade activities do not affect the terms of trade it faces (the small country assuaption): and b) there are no quota restrictions on consumption. 3

A "project" is defined as any small change in the composition of national production. We shall use the superscript "T" to denote traded comnodities and the superscript " $N$ " to denote non-traded conmodities. P denotes the set of traded commodities. $h$ the set on non-traded commodities. and $W$ the set of all goods. $C^{T}$ denotes aggregate spending on traded goods neasured at world prices,

$$
c^{T}=\sum_{i \in \not} p_{1} c_{1}^{T}
$$

Denote by $x_{1}$ the output of the $i$ 'th commodity. We can represent a project as a vector, 4

$$
d x=\left(d x_{1}\right)
$$

The analytical problen is to determine the effect of the project on national welfare once a now equilibrium is restored. We decompose the inpact on national welfare of the project into two elements: a) changes in the level of (current) utility of the representative coneuner, and b) the preeent value

3 See our previous paper for a discussion of the relation between shadow prices and quota restrictions.

4 As usual, negative lenents in the vector would represent inputs. 
of net changes in the trade surplus/deficit. The former measures the contemporary benefits of additional domestic spending, while changes in the foreign exchange balance inply future benefits and costs. 5 Letting dW, dU, and dF stand for changes in welfare, consuner utility, and the trade surplus respectively, we have:

$$
d W=d U+\lambda d F
$$

where $\lambda$ is the relative value of a unit increase in the trade surplus to a unit increase in present utility. 6

Our objective now is to relate $d U$ and $d F$ to changes in consumption levels, or alternatively to changes in domestic income and prices: and to relate these changes to the underlying perturbation $(d X)$. Current utility is just a function of the current levels of consumption. Letting $\mathrm{C}_{j}$ denote the consunption of the $1^{\text {'th }}$ commodity,

$$
d U=\underset{i \in y}{\sum}\left[\partial U / \partial c_{1}\right] d c_{1}
$$

Since the marginal utility of the i'th good is just equal to the price of the good times the marginal utility of income, we have rafter normalizing the narginal utility of incone at unity):

$$
d U=\sum_{i \in J_{1}} q_{1}
$$

where $q_{1}$ is the consuners' price of good 1 .

5 We simplify our analysis by assuming the consumers do not save: thus, the direct effect of an increase in their current incone is only an increase in current consumption. This also consistent with optimal investment/savings behavior by consumers, but not necessarily by the government at the same tine.

6 Our 1981 paper discusses the derivation of $\lambda$. which in general requires use of dynanic modeling. 
It is often convenient to represent the current utility by the indirect utility function, giving utility os a function of consumer prices, $q$, and domestic incone net of taxes and subsidies, Yd.

$$
u=v\left(q ; Y^{d}\right)
$$

Differentiating, we obtain

$$
d U=\sum_{i \epsilon_{i} y^{-}}\left[\partial V / \partial q_{i}\right] d q_{i}+\left[\partial v / \partial y^{d}\right] d y^{d}
$$

Using Roy's identity, this can be re-expressed as

$$
d U=V_{I}\left(d Y^{d}-\underset{i \in \in_{Q}}{\sum} c_{1} d q_{1}\right)
$$

where

$$
v_{i}=\partial V / \bar{a} y^{d}
$$

is the marginal utility of income, which it will be recalled we normalize to unity.

The change in the trade surplus, dF, can also be decomposed into two components: a) the direct foreign exchange value of the goods produced by the project, which we denote by $d Y w$, and $b$ ) the indirect foreign exchenge cost of changes in imports of consumption goods brought about by any donestic spending induced by the project, which we denote by $\mathrm{dC}^{\mathrm{T}}$. That is.

$$
\begin{aligned}
d F & =d Y^{\prime \prime}-d C^{T} \\
& =\sum_{i \in Q_{1}} p_{1} d x_{1}-\sum_{i \in q_{1}} d C_{1}^{T}
\end{aligned}
$$

where the p-vector represents international prices. 
Letting consumption of the i'th good be a function of consumer prices. q, and domestic income (net of taxes/subsidies) Yd:

$$
c_{i}=c_{i}\left(q, Y^{d}\right)
$$

and taking the total derivative of (7), we have

$$
d C_{i}=\left[\partial C_{i} / \partial Y^{d}\right] d Y^{d}+\sum_{i \in \mathcal{G}}\left[\partial C_{i} / \partial q_{j}\right] d q_{\}}
$$

Using (8), we can derive $d C^{T}$ as a function of dyd and dq. That is,

$$
d c^{T}=\sum_{i \in f} p_{i}\left(\partial c_{i}^{T} / \partial Y^{d}\right] d Y^{d}+\sum_{i \in \mathcal{E}} p_{i} \sum_{j \in g}\left[\partial c_{i}^{T} / \partial q_{j}\right] d q_{3}
$$

where the index $i$ covers only traded goods and the index $j$ includes non-traded goods as well. This can be further simplified to

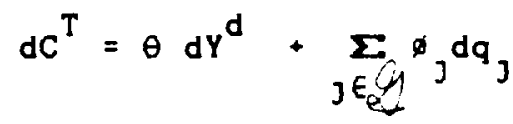

where

$$
\begin{aligned}
& \theta=\sum_{1 \in \tau} p_{i}\left[\partial c_{i}^{T} / \partial Y^{d}\right] \\
& \phi_{3}=\sum_{i \in \sigma^{\prime}} p_{1}\left[\bar{d} c_{1}^{T} / \partial q_{3}\right]
\end{aligned}
$$

Here, $\theta$ is the marginal propensity to import and ${ }_{3} q_{j} / C^{T}$ is the elasticity of imports with respect to the $J$ 'th price, both measured at internationel prices. Substituting ( $\left.9^{\prime}\right)$ into $(6)$ and $\left(5^{\prime}\right)$, while setting $V_{I}$ at unity, and then substituting into (1), we obtain the following expression for the change in national welfare as a function of the direct foreign exchange earnings of the project, the net change in domestic consumer spending, and the change in consumer prices brought about by the project:

$$
d W=d Y^{d}-C d q+\lambda\left(d Y^{W}-\theta d Y^{d}-\phi d q\right)
$$


where we employed the standard vector notation $C \cdot d q=\Sigma C_{i} d_{i}$. This equation takes account of the value of the project in international and domestic prices (through $d y$ w and dYd respectively), price and indirect tax changes (through dq). and changes in direct taxes and subsidies (through dyd).

We define the relative shadow price of any two goods $i$ and $J$ by

$$
\sigma_{i} / \varepsilon_{j}=\left[d w / d X_{i}\right] /\left[d w / d X_{j}\right]
$$

where the total derivatives take into account the full equilibrium adjustaent to the project-induced perturbation.

The rest of the general analysis consists of calculations of the values for dq and dYd essociated with any project (dX $X_{i}$, where the calculations must be done subject to any constrainte imposed and the marginal public finance behavior of the government. These are then introduced into (10) and (11) to derive shadow prices. We proceed to denonstrate how this can be done for several specific situations.

CONSUMPTION OF TRADED GOODS ONLY

We first consider cases where there is no consunption of non-traded goods. While admittedly of linited interest, these cases are useful as the nost straightforward lliustration of our approach and our conclusion that the border price rule holds only in special circunstances. We begin with the eimplest cases in which the government takes no action to adjustment domestic prices to the perturbations caused by a project, using only direct taxes and subsidies. We then consider cases where prices as well as direct taxes are adjusted to restore equ1libriun.

In cases where the equilibrium entails constant donestic prices. complete results are obteined easily. Here, (10) reduces to:

$$
d W=d Y^{d}+\lambda\left(d Y^{W}-\theta d Y^{d}\right)
$$


It is thus immediate that if the government acts to sterilize completely domestic expenditures from the project (so, dyd $=0$ ), then dW is proportional to the direct foreign exchange earnings of the project (dYw), so that the border price rule holds. This is the same as saying that the government shifts its portfolio from a traded commodity to foreign exchange. Setting $d y^{d}=0$ implies 100x taxation of the domestic value of the project with no accompanying lump-sum payments of these receipts.

If the government makes compensating adjustments (of any kind) to maintain the trade balance at its previous level, then the change in domestic expenditure, dyd, must be exactly equal to $1 / \theta$ times the change in foreign exchange directly due to the project, dYw. Hence,

$$
d W=d Y^{W} / \theta
$$

Again, the border price rule holds.

Hore generally, whenever the government imposes a 100 percent tax on domestic incone from the project and then allows domestic expenditure to increase by some fixed fraction of the project's foreign exchange earnings, relative shadow prices will equal relative border prices. These cese are those where:

$$
d Y^{d}=r d Y^{W}
$$

The first two cases above correspond to $r=0$ and $y=1 / \theta$ respectively.7 These results in turn are special cases of the still more general result that when all relevant total perturbations are simply proportional to dYw, shadow prices are also proportional to dYw.

7 An alternotive interpretation of this condition is that public sector firms are required to keep their books in terms of border prices and the tax rate on auch profita ia set equal to $1-\gamma$. 
Now consider the case where the change in domestic expenditure, dyd, is a function of the project itself and there is no net direct taxation. Here,

$$
d y^{d}=\sum_{i E_{j}} q_{i} d x_{i}
$$

If the economy is indifferent to accumulating one more unit of foreign exchange or incurring the foreign exchenge costs of increasing donestic consumption by one unit, then this implies $\lambda=1 / \theta$, a situation which we referred in our previous paper as one of optimal borrowing. Clearly, (12) implies that in this altuation, the border price rule is correct.

Finally, it is trivial to see that if relative domestic prices of the traded goods are the same as their relative border prices, then the relative shadow prices will also be in this ratio.

We have thus identified five circumstances where the border price rule will hold when donestic prices do not change and there are no non-traded consunption goods:

(1) When the government equilibrates to leave donestic expenditure after the project unchanged ("complete sterilization" of domestic expenditure):

(2) When the governaent equilibrates to leave a fixed trade balance after the project;

(3) When the level of foreign borrowing is set optinally before the project $(\lambda=1 / \theta)$;

(4) When the government uses direct taxation and lump-sum subsidies to increase donestic expenditures in proportion to the direct foreign exchange earninge of the project:

(5) When there is a non-distortionary trade regime (domestic prices proportional to international prices).

In all other cases, the border price rule cannot be directly applied.

Indeed, using (12) we can re-wite (11) as

$$
s_{1} / s=\left[a q_{1}+(1-a) p_{1}\right] /\left[a q_{3}+(1-a) p_{3}\right]
$$

where

$$
a=(1-\lambda \theta) /(1-\lambda \theta+\lambda)
$$


Here, the shadow prices are weighted averages of domestic and international prices. 8

Consumption Taxes

It is more difficult to get the border price rule to work when adjustments are made in consumption taxes. We will not develop a general rule of when border pricing is incorrect, but instead only consider several simple exanples.

It can be demongtrated straightforwardly that if the government changes all commodity prices in proportion, while using direct taxes to hold dyd equal to zero, then (10) will reduce to a form essentially identical to (12) because the commodity taxation will act identically to an income tax. In this situation all of the previous results will continue to hold, with the change in the price level playing the same role as changes in income did previously. Of greater interest are cases when only one consumption tax, e.g., that on good 1, is altered and no lump sum transfers/taxes are imposed, so that the change in domestic income equals the value of the project in domestic prices. Then, (10) reduces to

$$
d W=d Y^{d}-C_{1} d q_{1}+\lambda\left[d Y^{W}-\theta d Y^{d}-q_{1} d q_{1}\right]
$$

If the chenge in the tax on good 1 is just sufficient so that dF $=0,9$ the welfare measure further simplifies to

$$
\left.d W=\left[1+C_{1}\left(\theta / \Phi_{1}\right)\right] d Y^{d}-\left[C_{1} / \phi_{1}\right] d Y^{W}\right]
$$

8 Shadow prices are a positive weighted average (i.e., a > 0) provided that $\lambda \theta<1$.

9 Here, $d q_{1}=\left(d Y^{w}-\theta d Y^{d}\right) / \phi_{1}$. 
It is clear that the welfare change in (14') will be proportional to the project's border price value only if the total indirect tax rate on each good is the same for all goods, a special case of which is zero indirect taxes. Under these circumstances dYd would be proportional to dY because the coefficient of dyd becomes zero. Letting $(1+\tau)$ equal the common ratio of domestic to world prices, this result follows from the basic properties of the deand functions themselves. Engel aggregation implies that $\theta=1+\tau$ and Cournot eggregation implies that $\emptyset_{1}=-C_{i}(1+\tau)$. Otherwise, the border prices rule will fall. The sane conclusions hold if the consumption tax on good 1 is altered so as to keop contemporaneous utility constant, dU = 0 , allowing all benefits to derive through dF. 10

The general conclusion is that the "border price" rule fails unlese the various public finance instruments are set according some first- or secondbest rules derived from the solution of an optinizing problen. When taxes are set in a more ad hoc fashion, the "border price" rule cannot be expected to hold.

\section{IMCLUSIOH OF MOU-TRADED GOODS}

The more interesting and relevant cases are those where consunption of non-traded goods must also be considered. The involve additionel constraints on the ections of the government which must eccount for the narket equilibrium conditione that for each non-traded good

$$
c_{1}^{\prime \prime}=x_{1}^{H}
$$

If the project leaves output of any non-traded good, e.g.. good J. unchanged then (8) and (15) iaply

10 If $d U=0, d y d=c_{1} d q_{1}$; hence $d w=\lambda\left(d Y w-\left(\theta+H_{1} / c_{1}\right) d Y d\right)$. 


$$
0=\left[\partial C_{j}^{N} / \partial Y^{d}\right] d Y^{d}+\underset{i \epsilon_{j}}{\sum_{X}}\left(\partial C_{j}^{N} / \partial q_{i}\right] d q_{i}
$$

Equetions (16) impose a set of restrictions on the feasible set of actions which the government can take, above and beyond those in the previous coses.11 The simplest case is when all domestic prices, $q$, are left unchanged. This implies that dyd must also equal zero and from (11) that the border price rule will hold. This is the same as case (1) above where, because of complete sterilization, the entire effect of the project is on foreign borrowing.

Interesting results only energe when one or more domestic prices are allowed to change when a new project perturbs a pre-existing equilibrium. Each set of feasible adjustment rules would require a separate set of shadow price calculations. Here, we consider only a few specific cases.

For instance, suppose that in response to a perturbation, the government allows the exchange rate facing consumers to adjust, which changes the relative prices of traded and non-traded goods, but leaves the relative prices of traded goods as before. We further simplify by considering only one nontraded good, Cll. Taking this good as the numeraire, we can denote the change in the exchenge rate as dE. This implies

$$
d q_{1}=q_{1} d E
$$

Equations (16) and (17) imply that

$$
0=\left[\partial C^{N} / \partial y^{d}\right] d y^{d}+\sum_{i \sum_{l}}^{\sum} q_{1}\left[\partial c^{N} / \partial q_{1}\right] d E
$$

11 That is, the number of commodity taxes and direct taxes/subsidies which can be set independently is reduced by the number of non-traded goods. For non-traded commodities whose output changes due to a project, the left-hand side of (16) is not zero but the change in output of that non-traded good. 
and

$$
d E=-\left(\left[a c^{N} / a \gamma^{d}\right] / \sum_{i} E_{i} q_{i}\left[a c^{N} / \partial q_{i}\right]\right) d y^{d}
$$

where the index $i$ covers all the traded goods. Substituting the value for dE from (18') into (10) yields 12

$$
d W / m=d Y^{d}+\hat{\delta}\left(d Y^{w}-\hat{\theta} d Y^{d}\right)
$$

where

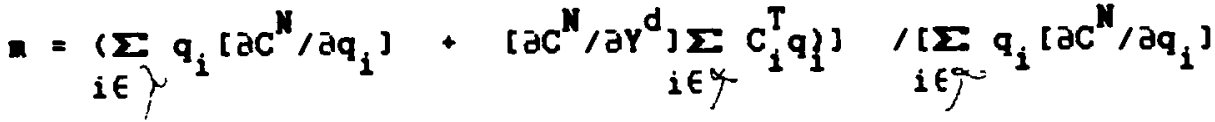

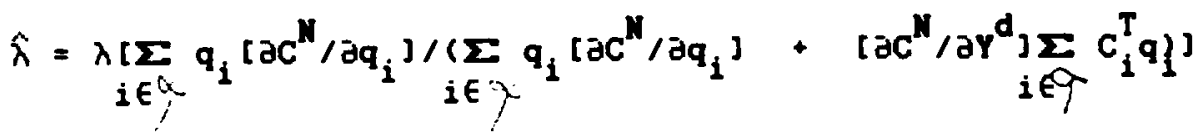

$$
\begin{aligned}
& \hat{\theta}=\theta-\left[\partial c^{N} / \partial \gamma^{d}\right]\left[\sum_{i \in q_{i}^{d}} q_{i}\right] /\left[\sum_{i \in q^{2}} q_{i}\left(\partial d / \partial q_{i}\right)\right]
\end{aligned}
$$

Using Euler's Theorem and defining $\alpha_{i}, \eta_{i}$, and $E_{i, i}$ os the expenditure share and the income and own-price elasticities of good $i$, the parameters $m, \hat{\lambda}$, and $\hat{\theta}$ can be written as:

$$
\begin{aligned}
& \square=\left(\alpha_{N} n_{N}+\epsilon_{N, N}\right) /\left(n_{N}+\epsilon_{M, N}\right) \\
& \hat{x}=\lambda\left(n_{N}+\epsilon_{N, N}\right) /\left(\alpha_{N} n_{N}+\epsilon_{N, N}\right) \\
& \hat{\theta}=\left[1 /\left(Y^{d}\left(n_{N}+\epsilon_{N, H}\right)\right]\right) \sum_{i \in Q^{d}} p_{1} c_{1}^{T}\left(n_{1} \epsilon_{N, H}-n_{N} \epsilon_{1, i}\right)
\end{aligned}
$$

12 Equation $\left(18^{\prime}\right)$ can also be writton in torms of denand elasticities. Using Euler's Theoren, dE would equal the percentage change in domeatic expenditure, dyd, times the ratio of the incone elesticity of the the nontraded good divided by the sum of the income and own-price elasticities of the non-traded good. The elasticity forn will often be more convenient in ompirical applications. 
Since (19) has the same form as (12), relating the change in welfare to the change in domestic expenditures and the direct foreign exchange earnings of the project, the same qualitative analysis can be applied. The only difference is that with the inclusion of the non-traded good, an equilibrating change in the consumers exchange rate is made. This change is incorporated in the "hats" used in (19). 13 Therefore, when the the only price changes are due to exchange rate changes, the border price rule will be correct:

(1) When the government equilibrates to leave domestic expenditure after the project unchanged ("complete sterilization" of domestic expend1ture):

(2) When the government equilibrates to leave a fixed trade balance after the project;

(3) When the level of foreign borrowing is set optinally before the project $(\hat{X}=1 / \hat{\theta})$;

(4) When the government uses direct taxation and lump-sum subsidies to increase domestic expenditures in proportion to the direct foreign exchange earninga of the project;

(5) When there is a non-distortionary trade regine (domestic prices proportional to international prices).

For any other taxation rules with exchange rate adjustment, relative shadow prices do not equal relative international prices.14 The general shadow price formula will be the same as (11'), but with the weight a now being

$$
\hat{a}=(1-\hat{\lambda} \hat{\theta}) /(1-\hat{\gamma} \hat{\theta}+\hat{\lambda})
$$

Note that as $\hat{X} \cdot \hat{\theta}$ becomes small, the shadow price ratio approaches the domestic price ratio.

13 This analysis, of course, requires that not aqual to zero. This will be the case as long as the $-E_{N, M} \neq \alpha_{N} n_{N}$.

14 It is easy to show that this analysis is unchenged for any price adjustment rule in which there 18 a one-to-one relationship between the consumer price changes and the change in expenditure. 
Alternatively, suppose that the adjustments to price and donestic expenditures are arbitrarily proportional to the induced disequilibrium in the foreign exchange market. In this case, the border price rule will be correct. To see this, we write

$$
\begin{aligned}
& d q_{i}=k_{i} d F \\
& d Y^{d}=k_{Y} d F
\end{aligned}
$$

The choice of $k_{y}$ must be consistent with equation (16), so that

$$
0=\operatorname{dF}\left(\left[\partial c^{N} / \partial Y^{d}\right] k_{Y}+\sum_{i \in \ell}\left[\partial c^{N} / \partial q_{i}\right] k_{i}\right)
$$

Substituting (21) into (5)' (with $V_{I}=1$ ), we see that the change in contemporaneous utility will be proportional to dF. Making the same substitution into ( 9 ) and then $\left(6^{\prime}\right)$ shows that dF will be proportional to dYw, thus proving that dW wll be proportional to the project's direct foreign exchange earnings and supporting the border price rule. The result etens fron government behavior which uses lump sum taxes/subsidies ( $k_{Y}$ ) to equilibrate In a way so that everything is proportional to the direct foreign exchange earnings of the project.

Obviously, there are wany other behevioral rules which a government could uee to re-equilibrate an econony. Each would require explicit calculation of the project-induced changes in prices and donetic expenditures and thon measured using (10). It should be clear, however, that there is no presumption that the reaulte will be shadow prices which correspond with international prices, except in special circunstances. 
CONCLUDING COHHENTS

We have demonstrated that it is appropriate to use relative border prices as the relative shadow prices for traded good only in special situations where the government. The underlying reason for this conclusion is that generally investment projects affect budget constraints in domestic prices and changes in these budget constraints lead to spending changes. These leakages, in turn, can affect both contenporaneous utility and the future utility (via the forelgn exchange balance) in ways such that knowing only the direct foreign exchange values of two projects is not sufficient to determine their ranking in terms of social welfare, or even to deternine if a project with positive foreign exchange earnings will have positive not social value.

Horeover, so long as there are non-traded goods, even if the government leeves tariffs unchenged (so that relative donestic prices of traded goods remain unchanged), unless the government completely neutralizes the induced change in donestic incone, there will be changes in the price of non-traded goods.15 The agnitudes of these price changes, and the consequent welfare effects, depend on all price and income olasticities.

Thus, although the border price rule will not, in general, be valid, we have developed a framework which allows shadow prices to be calculated. These calculations will in general necessitate knowledge of incone and price elasticities, as well as of the relative values of contemporaneous utility and future utility in the form of current foreign exchange holdinge. Fortunately for the practitioner this should not usually require additional estinatione since these are precisely the paraneters which ordinarily are used to

15 It should be noted that the price of non-traded goods, relative to traded goods, can be viewed as the real exchange rate. 
calculate shadow prices for non-traded goods and factors. Our results merely imply that this information be used also in the calculation of the shadow prices for traded goods.

It would be convenient for economic theorists if we could presume that governments set all of their policies optimally, in terms of a well defined social welfare function. It is apparent, however, that all too often we observe policies that seen inconsistent with any "ressonable" social welfare function, and indeed, with each other. This may be because we (the econonic analysts) have badly mis-specified the model of the econony, and in particular, the constraints facing the government. But it may also be because there is no reason to believe the outcones of the political/administrative processes should accord with a well defined sociel welfare function.

In these circumatances, what should be the nature of the advice given by econoniste? It is apparent that that advice predicated on the presumption that all other government actions are optimally set, to maximize a well defined social welfere function, is not only based on an incorrect description of the econony, but also, wore it taken seriously, might have eignificant advorse effects. There is a fashion anong sone economists to build into their welfare analyses certain "political constraints": but economists seen to have no particular acumen in ascertaining what are and are not political constraints. The best that oconomists can do is decribe how governments have in fact behaved in the past--how they have equilibrated the economy to various kinds of small perturbations including those project-related--and to dercribe the consequences--here, the shadow price implicetions--of alternative ways in which the economy might be equilibrated. We hope that our paper has clarified how this may be done. 


\section{REFERENCES}

Blitzer, C. R., Dasgupta, P. and Stiglitz, J.E. (1981), "Project Appraisal and Foreign Exchange Constraints," Economic Journal, vol. 91, pp. 58-74.

Dinwiddy, C. and Teal, F. (1986), "Project Appraisal and Foreign Exchange Constraints: A Comment," Economic Journal, this issue.

Tower, E. and Warr, P G. (1986), "On the Proportionality Between World Prices and Shadow Prices Under Alternative Equilibrating Mechanisms," mimeo. 